\title{
Convergence liberalism and the problem of disagreement concerning public justification*
}

\author{
Paul Billingham \\ Christ Church, University of Oxford
}

\begin{abstract}
The 'convergence conception' of political liberalism has become increasingly popular in recent years. Steven Wall has shown that convergence liberals face a serious dilemma in responding to disagreement about whether laws are publicly justified. What I call the 'conjunctive approach' to such disagreement threatens anarchism, while the 'nonconjunctive' approach appears to render convergence liberalism internally inconsistent. This paper defends the non-conjunctive approach, which holds that the correct view of public justification should be followed even if some citizens do not consider enacted laws to be publicly justified. My argument sheds light on the fundamental structure of convergence liberalism.
\end{abstract}

Keywords Convergence; political liberalism; public reason; reflexivity; self-defeat; Steven Wall; Kevin Vallier

The convergence conception of political liberalism - 'convergence liberalism', for short - has become established as a competitor to Rawlsian, 'consensus', public reason liberalism in recent years. ${ }^{1}$ The convergence and consensus views agree that laws must be publicly

\footnotetext{
* This is the Accepted Manuscript version of an article forthcoming in Canadian Journal of Philosophy.

Contact Paul Billingham paul.billingham@chch.ox.ac.uk
} 
justified - justified to all reasonable citizens by reasons that they can accept - in order to be legitimate. However, convergence liberals hold that public justification can be achieved through laws being justified to different citizens by different reasons, including reasons rooted in comprehensive doctrines, rather than requiring justification using a particular set of 'public reasons' that are shared by, or accessible to, all reasonable citizens.

Steven Wall (2013a) has presented a particularly important objection to convergence liberalism. ${ }^{2}$ Wall argues that the view faces grave problems due to the fact that citizens reasonably disagree about the idea of public justification itself. Indeed, this kind of disagreement threatens convergence liberalism with self-defeat. ${ }^{3}$

As I explain in detail below, Wall argues that convergence liberals must endorse the reflexivity requirement (RR), which states that a public justification principle (PJP) can only be a genuine moral requirement if it is itself publicly justified. Rejecting RR would make convergence liberalism internally inconsistent, because it would permit the imposition of laws that some citizens do not believe to be publicly justified. This is incompatible with convergence liberalism's underlying rationale of avoiding so-called 'moral authoritarianism'. Endorsing RR, however, leads convergence liberalism to have very unpalatable implications, since few, if any, laws will be publicly justified. Convergence liberals can offer no response to disagreement concerning public justification that is consistent with the view's underlying motivation but does not threaten anarchism.

\footnotetext{
${ }^{1}$ Mainly through the work of Gaus (2011) and Vallier (2014a). See also Gaus \& Vallier (2009). The classic statement of the consensus view is of course Rawls (2005).

${ }^{2}$ For other objections, see Quong (2011, 265-273); Enoch (2013); Boettcher (2015). For replies, see, respectively, Billingham (2016); Gaus (2015a); Vallier (2016a).

${ }^{3}$ Wall (2002) argues that the consensus view is also self-defeating.
} 
Wall highlights an important issue for convergence liberals: how to respond to disagreement about public justification itself, and thus about whether particular laws are publicly justified. However, he misrepresents the objection by framing it in terms of RR. Convergence liberalism can avoid the 'moral authoritarianism' horn of Wall's dilemma while continuing to reject RR, but would still face the 'anarchism' horn. Both horns are thus independent of RR. RR does no work in the objection, and convergence liberalism is not threatened with selfdefeat.

Nonetheless, Wall is correct that convergence liberals face a dilemma concerning whether laws can be publicly justified despite some reasonable citizens believing that they are not. Convergence liberalism says that in order to avoid moral authoritarianism laws should only be enacted when they are justified to all reasonable citizens on the basis of their own beliefs and values. Enacting laws that some do not consider to be publicly justified seems to violate this commitment, and thus to make the view internally inconsistent. Refraining from enacting such laws threatens anarchism, however, given the potentially vast range of views about when laws are and are not publicly justified. Convergence liberals explicitly reject anarchism, and believe that their view can justify central liberal institutions and policies. If these results can only be achieved through internal inconsistency then this is sufficient reason to reject the view.

This paper defends convergence liberalism from this objection. I argue that convergence liberals must maintain that the correct account of public justification should be followed even when some citizens believe that laws are not publicly justified. Contra Wall, this is not morally authoritarian, so it does not make the view internally inconsistent. The commitment 
to respecting citizens' own beliefs and values need not extend to respecting their beliefs about legitimacy itself. Further, the fact that convergence liberals must respond in this way to disagreement concerning public justification helps us gain a clearer understanding of the fundamental structure of the view, by highlighting the way that convergence liberals must hold that their specific understanding of public justification is correct.

The paper is structured as follows. Section 1 provides an outline of convergence liberalism, as it is presented by Gerald Gaus and Kevin Vallier. In Section 2 I review the way that RR threatens public reason views with self-defeat, and present Wall's objection to convergence liberalism. I show that Wall is mistaken to frame his argument in terms of RR, but that his objection nonetheless presents an important dilemma. Section 3 considers a recent response from Vallier. I argue that it fails, but that understanding why this is the case reveals a further way that we must re-interpret Wall's objection: it must refer to disagreement among actual, rather than idealised, citizens. This observation paves the way for the response sketched in the previous paragraph, which I defend in Section 4. Finally, in Section 5 I discuss two costs that my response might seem to involve, from a convergence liberal perspective: lessening the difference between convergence liberalism and rival views and abandoning the realisation of a publicly justified social morality. I argue that neither apparent cost withstands critical scrutiny.

My arguments in this paper do not constitute a positive argument for convergence liberalism. In the course of the paper I will mention some of the claims made by convergence liberals to motivate the view, but will not defend those claims. There might be other good reasons to reject convergence liberalism, even if my argument succeeds. The objection I consider here is a particularly important one, however, since it threatens convergence liberalism with internal 
inconsistency. The view is only viable if this objection can be rebutted. It is therefore crucial to demonstrate how convergence liberals can rebut it - especially since doing so has wider implications for our understanding of the theory.

\section{Convergence liberalism}

The convergence liberal version of PJP states that a coercive ${ }^{4}$ law is permissibly imposed only if every reasonable citizen has sufficient intelligible reason to accept it on the basis of her own evaluative standards. PJP is seen as a necessary condition for the legitimacy of laws. ${ }^{5}$ Respect for citizens' moral freedom and equality requires that laws are imposed only if they are justified to each citizen by their own evaluative standards - their own values, norms, conceptions of the good, and so on. Several features of this view require comment.

First, convergence liberals define citizens' justificatory reasons in reference to their own beliefs and values, at least when it comes to public justification. ${ }^{6}$ Citizens' own evaluative standards must give them sufficient reason to endorse the law. This does not mean that an individual's belief-value set, the set of propositions or claims that she affirms, is taken as

\footnotetext{
${ }^{4}$ I focus exclusively on coercive laws in this paper, because many political liberals ground public justification in the need for coercion to be justified to the coerced. Some theorists believe that all laws are coercive, but I take no view on that here.

${ }^{5}$ PJP is not a sufficient condition for legitimacy. Another necessary condition generally endorsed by convergence liberals is democratic enactment, which is required to choose among laws that fulfil PJP. See Gaus (2011, 451-454); Vallier (2014a, 99, 131).

${ }^{6}$ Gaus $(2010 \mathrm{a}, 184)$ calls this a 'practical internalism' about reasons. He notes that 'this internal-reasons requirement is not a metaphysical thesis about what reasons there are, but a doctrine about what reasons a person has access to' $(209$, fn. 25).
} 
given, however, such that a proposition is justified to her only if she believes it. She might have reasoned badly or lack easily attainable empirical information, or her belief-value set might contain contradictions that prevent her from endorsing the proposition in question. Public justification should not be blocked by these sorts of obvious epistemic defects. Convergence liberals thus endorse 'moderate idealisation', which attributes to citizens easily attainable empirical information and corrects obvious reasoning errors (Vallier 2014a, 145180; Gaus 2011, 232-257). This 'idealization abstracts from citizens' present belief-value sets to determine the reasons to which they are plausibly committed' (Vallier 2014a, 147). This moves the account of citizens' reasons away from being an 'actual acceptance' view, but the changes made to a citizen's belief-value set are ones that are epistemically accessible to her. They are changes that she would herself make if she engaged in a 'respectable amount' of good reasoning (Gaus 2011, 250). ${ }^{7}$

Convergence liberalism thus invokes a justificatory constituency containing moderately idealised versions of actual citizens - 'Members of the Public', as Gaus (2011, 266-267) calls them. This can be helpfully contrasted with Jonathan Quong's version of consensus public reason liberalism. Quong (2011, 137-170) endorses the 'internal conception', according to which the justificatory constituency is an entirely hypothetical group of agents, defined by their endorsement of the ideal of society as a fair system of social cooperation between free and equal citizens and a set of liberal political values and principles that are seen as derived from that ideal - including the idea of public reason itself. For Quong, laws are publicly justified when their justification appeals to the values and principles that are shared by this hypothetical constituency. ${ }^{8}$

\footnotetext{
${ }^{7}$ All future references to citizens' 'reasons' are to the justificatory reasons identified via moderate idealisation.

${ }^{8}$ Gaus (2012) and Vallier (2014b) have both written critiques of Quong's view.
} 
Second, according to convergence liberalism the reasons that justify a law to a citizen need not be ones that others can share or accept. Instead, those reasons merely need to be intelligible to others - reasons that others can recognise as epistemically justified for the individual on the basis of her own evaluative standards (Vallier 2014a, 103-144). Given reasonable pluralism, citizens endorse a variety of different conceptions of the good, and so hold a variety of evaluative standards. Laws can be justified to different citizens by different intelligible reasons. This contrasts with consensus public reason liberalism, where public justification involves appeal to a specific set of 'public reasons', which are shareable by, or accessible to, all reasonable citizens (Quong 2011, 261-265; Vallier 2014a, 104-111).

Third, citizens must have sufficient, or conclusive, reason to endorse laws. It is not enough for a citizen to merely have some intelligible reason for a law. After all, she might have stronger opposing reasons. In Vallier's $(2012,151)$ words, 'it is only when coercion is justified by conclusive reasons that we can say that each citizen is committed to the coercion proposed.' Gaus (2010a, 195) concurs: 'Unless the reason is conclusive... [the citizen], given her evaluative standards, does not have an all-things-considered reason to endorse the coercion, so it is not justified.'

Convergence liberals thus require an account of sufficient reasons. An extremely demanding view would be that one has sufficient reason only if one considers the law to be the best justified among all available options. This requirement seems too strong, however. If the aim is to ensure that coercion is justified to every citizen, then what matters is that each considers the coercion preferable to not being coerced. Each must have all-things-considered reason to consider a law better than having no law on the relevant issue; none may have decisive 
reasons to reject the law. A citizen has sufficient reason to accept all laws that her (moderately idealised) belief-value set ranks above not having any such law. Those laws are 'conclusively justified' to her. ${ }^{9}$ Gaus $(2011,321-322)$ calls this the citizen's 'eligible set'.

Laws are publicly justified when they are in every citizen's eligible set. Such laws are in the 'socially eligible set'. Each citizen, 'drawing on her evaluative standards, has an all-thingsconsidered reason to rank living under the law's coercion as better than having no coercive law at all on this matter' (Gaus 2010a, 196).

Fourth, I am focusing here on the public justification of coercive laws. Gaus's theory is broader than this. He offers a general account of moral authority, holding that all of social morality must be publicly justified in order for moral demands to be legitimately imposed. His view with regard to laws is an application of this wider view, since laws impose moral demands upon citizens and thus must be publicly justified in the same way as all such demands. I am not engaging with this broader view of public justification here. ${ }^{10}$

Finally, in addition to the epistemic idealisation mentioned above, convergence liberalism requires a conception of normative reasonableness - of the beliefs, values, and dispositions one must possess in order to be within the constituency of reasonable citizens to whom justification is owed. Gaus (2012) holds that justification is owed to all 'good-willed moral agents'. ${ }^{11}$ Such individuals believe that other citizens are morally free and equal, wish to live with others on fair terms, and understand the basic give-and-take and impartiality of moral

\footnotetext{
${ }^{9}$ To be precise, these laws are 'conclusively justified' compared to having no law, and are 'inconclusively justified' compared to each other.

${ }^{10}$ I return to this point in Section 5.

${ }^{11}$ See also Vallier $(2014 \mathrm{~b}, 12)$.
} 
life. Sociopaths, pure egoists, and fundamentalists who wish to repress other reasonable points of view are excluded. But this is a fairly weak normative standard. Citizens need not endorse any particular interpretation of the implications of others' freedom and equality or the meaning of 'fair terms of cooperation' in order to qualify as reasonable. Importantly, endorsing PJP itself is not a requirement of reasonableness. As I note below, this contrasts with several prominent consensus public reason liberal theorists' views. ${ }^{12}$

Overall, then, convergence liberals hold that laws must be conclusively justified to all goodwilled moral agents on the basis of their own evaluative standards. All must have sufficient reasons within their own moderately idealised belief-value sets to consider each law better than having no law in the relevant policy area.

\section{Reflexivity, self-defeat, and disagreement concerning public justification}

\subsection{Reflexivity and self-defeat}

The self-defeat objection to political liberalism is rooted in the idea that public justification principles must apply to themselves. The reflexivity requirement (RR) states that a PJP can

only be a genuine moral requirement if it is itself publicly justified. ${ }^{13}$ If a political liberal view must endorse RR but some reasonable citizens reject (its version of) PJP, such that RR is not satisfied, then the view is self-defeating. PJP cannot be a genuine moral requirement, because it fails its own test.

\footnotetext{
${ }^{12}$ See footnote 14 , below.

${ }^{13}$ As far as I am aware, this idea was first discussed by Solum (1993). See also D'Agostino (2013).
} 
It is often thought that this objection only applies to consensus public reason liberalism (Lister 2013, 125). The consensus PJP states that no consideration can be appealed to within political decision-making unless it is acceptable to all reasonable citizens. PJP is itself a reason that is invoked within political decision-making, however. The principle is therefore reflexive, and potentially self-defeating. If it does not fulfil RR then it fails its own test, and excludes itself from political decision-making. It avoids self-defeat only if it satisfies RR i.e. only if no reasonable citizen rejects it. ${ }^{14}$

The convergence liberal PJP, in contrast, does not appear to be reflexive. ${ }^{15}$ It states that coercive laws must be conclusively justified to all reasonable citizens. This principle is not itself a coercive law, and so it does not apply to itself. It therefore need not satisfy RR. Convergence liberals believe that only laws that every reasonable citizen has sufficient reason to endorse should be imposed. But one need not also believe that all reasonable citizens accept this principle in order to consistently hold it and use it to assess the legitimacy of laws. Since convergence liberalism need not satisfy RR, it is not self-defeating, even if some reasonable citizens reject it.

Wall $(2013 \mathrm{a}, 164-8)$ argues that this is mistaken, however, because the rationale behind convergence liberalism is such that PJP must apply to itself. Even if PJP's formal content

\footnotetext{
${ }^{14}$ Several public reason liberals hold this to be the case, and thus make endorsement of PJP one of the criteria for reasonableness. See Estlund (2008, 53-61); Quong (2011, 37-39); Lister (2013, 127-128). Rawls also implies this, since he states that reasonable citizens offer one another terms of cooperation that all can accept and recognise the implications of reasonable pluralism for the use of public reason. See Rawls $(2005,49-61,446-$ 447).

${ }^{15}$ Gaus has repeatedly argued as much: Gaus (2011, 225-228; 1996, 175-178); D’Agostino \& Gaus (1998, xviiixxi).
} 
does not make it reflexive, its rationale does. Specifically, he claims that if PJP does not satisfy RR then convergence liberalism can be objected to on precisely the same grounds that convergence liberals object to what I will call the 'right reasons view' - the view that laws can be legitimately imposed whenever they are supported by true or right reasons. Convergence liberals reject such 'correctness-based justification' ${ }^{16}$ as sufficient to legitimise laws, because they consider it wrong to coerce a moral equal by appeal to values and ideals that she reasonably rejects. Gaus $(2011,15)$ writes that 'moral persons are all equally authoritative interpreters of the demands that morality places on one.' An implication of this is that none can permissibly force others to follow laws that are not conclusively justified to them. Moral freedom among moral equals involves freedom from being forced to follow another's interpretation of morality's demands, if the relevant law is not within one's own eligible set. Given reasonable pluralism among citizens' evaluative standards, the right reasons view involves claims to coercive authority for the views of some that is incompatible with respecting others as morally free and equal.

The convergence liberal rationale for PJP is thus the avoidance of 'moral authoritarianism' (Gaus 2011, 30). Wall claims that convergence liberalism is itself morally authoritarian if PJP fails to satisfy RR.

\subsection{An example}

The easiest way to explore this claim is by considering an example. ${ }^{17}$ The individuals within this example are discussing what laws would be legitimate were they democratically enacted within their polity. ${ }^{18}$

\footnotetext{
${ }^{16}$ This term is from Wall (2002).

${ }^{17}$ Aspects of this example are based on Wall's (2013a, 165-167) 'Reds and Greens' case.
} 
Andy endorses the 'right reasons view'. He believes that laws with a sound justification are legitimate. He is also religious, and believes that scripture shows law $\mathrm{L}_{1}$ to be required by justice. $\mathrm{L}_{1}$ can thus be permissibly enforced upon everyone within the polity, since it is justified by the correct theory of justice. ${ }^{19}$

Becky is a convergence liberal, and considers the imposition of $\mathrm{L}_{1}$ to be impermissible, because it is not within the socially eligible set. Some reasonable citizens have decisive reason to reject it, so its imposition would fail to treat them as morally free and equal. $\mathrm{L}_{1}$ would force everyone to comply with a particular understanding of morality, which many reasonably reject. Its enactment would be 'morally authoritarian'.

Becky believes that another law, $\mathrm{L}_{2}$, is in the socially eligible set. $\mathrm{L}_{2}$ is a law aimed at lowering carbon emissions, which makes it a legal requirement that all cars be fitted with new technology that reduces the environmental impact of exhaust gas. Existing car-owners must purchase, and regularly service, this technology, at their own expense. Becky believes that $L_{2}$ is justified to every citizen - each has sufficient reason from within her own beliefvalue set, appropriately moderately idealised, to accept $\mathrm{L}_{2}$ as preferable to having no law on this issue. Moderately idealised citizens - Members of the Public (MOPs) - would recognise the dangers of pollution and climate change, accept the scientific evidence in favour of the

\footnotetext{
${ }^{18}$ Assuming that other necessary conditions for legitimacy, such as constitutionality, were also fulfilled. For reasons that I lack space to explore here, proponents of convergence liberalism hold that the view does not impose obligations upon ordinary citizens only to support laws that are publicly justified (Gaus \& Vallier 2009, 65-70; Gaus 2010b; Vallier 2014a, 181-190; see also Billingham (forthcoming)). The individuals in the example are thus not (necessarily) deciding whether to advocate or vote for particular laws.
}

${ }^{19}$ Clearly Andy would need a more complex argument. I simplify here for the sake of brevity. 
technology, and thus consider $\mathrm{L}_{2}$ 's benefits to outweigh the relatively small financial costs. $\mathrm{L}_{2}$ 's enactment therefore respects all citizens as free and equal.

Colin is also a convergence liberal, but believes that $\mathrm{L}_{2}$ is not in the socially eligible set. Colin believes that Becky has over-idealised citizens' belief-value sets. The scientific evidence is in fact disputed, so some MOPs will not believe that the law achieves its ends. Further, some will consider the benefits in terms of reduced emissions to be outweighed by the financial and administrative costs imposed upon them. Becky removes these objections to the law by over-idealising, supposing that all MOPs accept the scientific evidence in favour of the technology and thus consider the benefits of the law to be very great. It is only on this basis that she believes $\mathrm{L}_{2}$ to be justified to them by 'their own' evaluative standards. When we use a more appropriate, more moderate, level of idealisation we find that $\mathrm{L}_{2}$ is not justified to some. The enactment of $\mathrm{L}_{2}$ would coerce those citizens in ways that they lack sufficient reason to accept.

Becky and Colin disagree over what Wall (2013a, 164) calls 'the test of public justification'. Whether a law is seen as publicly justified, from a convergence liberal perspective, depends on the precise specification of PJP. This specification elucidates the standards of reasonableness, intelligibility and idealisation, in order to identify the reasons that citizens have for and against laws, and thus what laws are justified to them. For example, this specification must include an account of what Jason Tyndal (2015) calls 'information acquisition responsibilities'. One's view of when citizens have a responsibility to acquire particular pieces of information, such as scientific evidence, will dictate what information one imputes to the moderately idealised versions of those citizens. This will then affect the reasons that one's account says that those citizens have, and thus what laws one considers 
justified to them. The same is true of one's view of the degree of coherence that idealisation should create in citizens' belief-value sets (Vallier 2014a, 162-163). Different specifications of PJP will involve different standards of coherence, and will thus impute different reasons to citizens. One must apply a particular specification of PJP - a particular test of public justification - in order to determine whether a law is publicly justified.

Becky and Colin disagree over the test of public justification, due to their differing views of the appropriate level of idealisation. This leads them to disagree over whether $L_{2}$ is in the socially eligible set. Imagine that Becky claims that $\mathrm{L}_{2}$ can be legitimately enacted despite Colin's protests. She has listened to his arguments and taken his view into account, but she considers him mistaken. According to Becky's understanding of PJP, $\mathrm{L}_{2}$ passes the test of public justification, and so it is publicly justified. Its enactment would respect all citizens as free and equal. Colin rejects this, arguing that there are some citizens who would not be so respected if $\mathrm{L}_{2}$ were enacted, since they have decisive reason to reject $\mathrm{L}_{2}$. According to his understanding of PJP, $\mathrm{L}_{2}$ is not publicly justified. Perhaps $\mathrm{L}_{2}$ is not even justified to Colin, according to his test. Colin can recognise that Becky believes the law to be justified to everyone, including himself, but part of the explanation for this is her test of public justification, which he (reasonably) rejects. The enactment of $\mathrm{L}_{2}$ would involve the imposition of Becky's particular, and controversial, understanding of PJP upon all citizens, even those who reject it. According to Wall, this would itself be morally authoritarian Colin's understanding of the demands of morality would not be treated as equally authoritative as Becky's.

Notice that Colin's objection to the putative legitimacy of $L_{2}$ is similar to Becky's objection to $\mathrm{L}_{1}$. Colin claims that $\mathrm{L}_{2}$ is not conclusively justified to all citizens, just as Becky claims 
this about $\mathrm{L}_{1}$. We might therefore suppose that if Becky's objection to $\mathrm{L}_{1}$ is sound, as convergence liberals believe, then Colin's objection to $\mathrm{L}_{2}$ is also sound. Even though Andy believes that $\mathrm{L}_{1}$ is justified according to the correct view of morality, given reasonable disagreement he should recognise that $\mathrm{L}_{1}$ cannot be legitimately enacted. Similarly, even though Becky believes that $\mathrm{L}_{2}$ is publicly justified according to the correct test of public justification, given reasonable disagreement over that test she should recognise that $\mathrm{L}_{2}$ cannot be legitimately enacted. Or so it seems.

\subsection{The dilemma}

According to Wall, the lesson from such examples is that convergence liberalism will itself be morally authoritarian, and thus condemned by its own rationale, if a particular controversial test of public justification is followed. Further, Wall argues that the source of the problem here is the rejection of RR. If convergence liberals are to avoid moral authoritarianism then they must affirm RR. This is a worrying prospect, since RR brings concerns about self-defeat back into the picture. ${ }^{20}$

Wall missteps here, however. Even if his assessment of cases such as that of Becky and Colin is correct - which I will later dispute - it does not show that convergence liberals must endorse RR. The key feature of this case is not that Colin rejects PJP, since he doesn't, and nor is it the fact that Colin rejects Becky's specific test of public justification, although he does. The salient feature is that Colin considers $L_{2}$ to be outside the socially eligible set, on the basis of his $o w n$ test. The way to avoid moral authoritarianism is therefore to hold that a

${ }^{20}$ Especially since convergence liberals reject the idea that endorsement of PJP can be made a criterion for reasonableness. Vallier $(2016 \mathrm{~b}, 350)$ writes that this 'reply to the self-defeat objection makes the justificatory public, the set of people to whom coercion must be justified, far too narrow. Reasonable people are bound to disagree about whether public justification requirements are genuine moral requirements.' 
law can only be permissibly enforced when no reasonable citizen believes that it is outside the socially eligible set - i.e. when the law passes every test of public justification endorsed by some citizen. I will call this the 'conjunctive approach'. On this approach, $\mathrm{L}_{2}$ should not be enacted, since Colin believes that it falls outside the socially eligible set.

Wall (2013a, 168) himself suggests the conjunctive approach as a way of responding to his argument. $^{21}$ However, he construes it as a way of incorporating RR into convergence liberalism. This is a mistake. RR states that PJP can only be a genuine moral requirement if PJP is itself publicly justified. In our context, Wall (164) applies RR at the level of a specific test of public justification, and construes it as saying that every citizen must endorse a test of public justification if that test is to be used to assess the legitimacy of laws. The conjunctive approach is distinct from this requirement, however. It says that a law should only be enacted when every test of public justification endorsed by some reasonable citizen concludes that it is within the socially eligible set. This does not mean that there is any particular test that every citizen endorses, or even that every reasonable citizen affirms some such test. Some citizens might have no view about PJP at all, or might even reject it. The conjunctive approach can thus be satisfied in cases where RR is not fulfilled. But this is unproblematic, as long as none consider prospective laws to be publicly unjustified. Moral authoritarianism is avoided by not enacting any laws that some reasonable citizen believes fall outside the socially eligible set, on the basis of her own understanding of the test of public justification.

If Wall's argument concerning moral authoritarianism is successful then it shows that convergence liberals should affirm the conjunctive approach, not that they should affirm RR. Wall seeks to use the moral authoritarianism argument to make the case for RR, but one can

\footnotetext{
${ }^{21}$ I take the term 'conjunctive' from Wall.
} 
affirm the conjunctive approach while rejecting $\mathrm{RR}$, using the standard argument that convergence liberalism's PJP does not apply to itself. ${ }^{22}$ This shows that the issue that Wall highlights is distinct from the question of reflexivity.

Unlike consensus public reason liberalism, convergence liberalism need not satisfy RR and is not threatened by self-defeat. ${ }^{23} B u t$ convergence liberals still face the question of how to respond to disagreement about the specification of PJP, and thus about whether particular laws are publicly justified. This is the question that Wall's argument raises.

One response to disagreement concerning public justification is to hold that laws can be enacted in line with a test of public justification even if some citizens do not believe those laws to be publicly justified. Wall argues that this response, 'the non-conjunctive approach', is morally authoritarian, and so makes convergence liberalism internally inconsistent. This was the lesson of the Becky and Colin example.

The conjunctive approach is an alternative response to disagreement concerning public justification. It holds that laws can only be enacted if no reasonable citizen believes that they ${ }^{22}$ i.e. The argument I stated on p. 9.

${ }^{23}$ One might suggest that the internal inconsistency purportedly threatened by the non-conjunctive approach is itself a form of self-defeat. But this internal inconsistency is distinct from the kind of self-defeat associated with a view that must fulfil RR and fails to do so. The standard self-defeat objection says that PJP is itself within the domain of things that PJP claims must be acceptable to all in order to be genuine moral requirements, yet PJP is not acceptable to all, and it therefore cannot be a genuine moral requirement - in effect, it rules itself out. Whereas the objection to the non-conjunctive approach is that it is (purportedly) inconsistent with convergence liberalism's underlying rationale of avoiding moral authoritarianism, so it is impugned by the very value that justifies the view. These are distinct objections. Even if both can be seen as kinds of self-defeat, my point that the dilemma that Wall raises is independent of RR still stands. 
fall outside the socially eligible set. This approach brings its own serious problem, however: few, if any, laws are likely to satisfy it. When we consider the range of possible tests of public justification, 'the prospects for substantial overlap become vanishingly small' (Wall 2013a, 168). The conjunctive approach threatens anarchism. These unpalatable consequences will themselves strike many as reason to reject this approach.

Convergence liberals thus face a dilemma. The conjunctive approach threatens anarchism, but the non-conjunctive approach appears to make convergence liberalism internally inconsistent. Convergence liberals' vision of having political arrangements yet avoiding moral authoritarianism seemingly cannot be realised (Wall 2013a, 169). ${ }^{24}$

\section{Vallier's response and the failure of the conjunctive approach}

In Section 4 I will argue that convergence liberals should embrace the non-conjunctive horn of the dilemma, and defend this approach from the charge of moral authoritarianism. First, however, we should consider Vallier's recent response to Wall, which will reveal the shortcomings of the conjunctive approach. Vallier (2016b) seeks to show that public reason views of all types are not self-defeating, but he also addresses Wall's specific critique of convergence liberalism.

Vallier's argument has two main parts. First, he argues that even if citizens reject PJP, or any particular specification of it, they can still have reasons to accept a law from their own perspective. The law can thus be publicly justified even though some reasonably reject PJP. PJP itself need not enter into people's reasons for accepting the law. While PJP explains why

\footnotetext{
${ }^{24}$ See also Wall (2013b), especially pp. 491-493.
} 
the law can be legitimately enacted, from the convergence liberal perspective, it is not usually itself a reason that justifies the law to citizens. Instead, citizens usually have other reasons to endorse a law, even if they reject PJP.

Second, Vallier argues that if there are a limited set of cases where PJP itself $i s$ essential to the justification of laws to citizens who reject it, then those laws should simply not be imposed upon those citizens. The laws should either not be enacted or only enacted with exemptions. Vallier claims that Wall's argument only gives us reason to reject convergence liberalism if there are examples of 'critically important laws' that cannot be justified without PJP itself being part of the justification. But there are no such examples, since individuals will always have other reasons from within their evaluative standards to endorse truly essential laws.

At first blush, Vallier does not seem to grapple with the heart of the dilemma. He argues that citizens will usually have 'other reasons' that justify a law to them, even if they reject PJP. Yet the problem Wall highlights is that the specification of PJP itself identifies citizens' justificatory reasons. We can only say what 'other reasons' citizens have to endorse a law by referencing a specific test of public justification, which details the form that moderate idealisation takes. Citizens who reject that test might well reject this account of their own reasons, and so will not consider themselves to have the 'other reasons' that we believe them to have. Vallier's argument seems to assume that all citizens agree on the specification of the reasons that they have; their disagreement is simply over whether PJP needs to be fulfilled in order for laws to be legitimate. But it is a specific understanding of PJP itself that does the work of specifying what reasons citizens have. There is no conception of citizens' reasons independent of a particular test of public justification, so no independent conception we can 
appeal to in order to say that citizens have 'other reasons' for the law. It might thus appear that Vallier must rely on a particular test of public justification in order to claim that citizens have other reasons for the law. Some citizens might reject that test and its account of their reasons, and thus not agree that the law is justified to them. Further, this applies to all laws, even critically important ones.

Certainly, Vallier is right that PJP itself does not normally feature as a reason that justifies laws to citizens. If $\mathrm{L}_{2}$ is justified to Colin (as Becky believes) then this is because his evaluative standards give him all-things-considered reason to conclude that $\mathrm{L}_{2}$ is better than having no law requiring car-owners to adopt emissions-reducing technologies. PJP itself is not one of his reasons for endorsing $\mathrm{L}_{2}$. However, it is a specific interpretation of PJP that identifies the reasons that Colin has, given his belief-value set, using its account of moderate idealisation and intelligibility. This test of public justification thus plays an essential role in explaining why $\mathrm{L}_{2}$ is justified to Colin, since it attributes to him acceptance of the relevant scientific evidence and thus recognition of the law's benefits. Colin rejects that test, and the account of his own reasons that is derived from it, and believes that $\mathrm{L}_{2}$ is not justified to him. He holds a different test of justification, so does not believe that he has the reasons for $\mathrm{L}_{2}$ that Becky believes him to have.

Nonetheless, Vallier's response could still succeed, if each individual's beliefs about her own reasons lead her to recognise the law as justified to her. It could be that even citizens who reject PJP, or our specific understanding of it, nonetheless recognise that they have sufficient reason to endorse a given law, and that we should only enact laws when this is the case. Vallier might claim that this will in fact be the case for all critically important laws. All citizens will recognise that they have sufficient reason to endorse laws instituting basic liberal 
rights, for example. This makes Vallier's response a defence of the conjunctive approach. We can understand Vallier as defending that approach by denying that it has the unpalatable, anarchistic, implications that Wall claims.

Even if Vallier is right about this, however, ${ }^{25}$ there is a deeper problem with his response, which we can see by asking who the 'citizens' that it refers to are. One option is that it is actual citizens. All actual citizens must recognise laws as justified to them. But it seems strange to tie convergence liberalism to actual citizens' own judgments about their reasons in this way. As I explained earlier, convergence liberals endorse moderate idealisation. The reasons that citizens have are identified via this process, rather than merely relying on citizens' own beliefs about their reasons.

We should therefore instead understand Vallier's claim to be that every moderately idealised citizen - every MOP - can recognise that they have sufficient reasons for laws, even if they reject PJP. For all critically important laws, MOPs' beliefs about their own reasons will lead them to endorse the law.

The problem here is that it is a particular specification of PJP that determines the correct form of idealisation, and thus what reasons MOPs recognise. There is no specification of the reasons of moderately idealised agents independent of a specific test of public justification. Agents idealised in the way that a particular account specifies will of course recognise all the reasons that that account says they have, and thus will endorse laws based on those reasons. But it is the particular specification of PJP that is doing the work in identifying those reasons,

\footnotetext{
${ }^{25}$ This partly depends on one's view of what constitute 'critically important laws'. Vallier might well consider fewer laws 'critically important' than do many other liberal theorists.
} 
and thus showing that laws are publicly justified. When we ask whether all MOPs recognise a law as justified to them we must already assume some specific test of public justification, since it is that test that furnishes us with the standard of moderate idealisation used to define MOPs' beliefs. Becky believes that a moderately idealised version of Colin would recognise $\mathrm{L}_{2}$ as justified to him, since he would recognise all of the reasons that her standard of moderate idealisation says that he has.

This is not to say that all MOPs endorse PJP itself, or any specific test of public justification. The point instead is that MOPs, by their very construction, recognise the justificatory reasons that the standard of moderate idealisation we have applied says that they have. They will recognise that they have sufficient reason to endorse whatever laws our test of public justification says are publicly justified - precisely because they are modelled to recognise all the reasons that our standard of moderate idealisation says that they have. MOPs do not disagree about the reasons that they have, and therefore do not disagree about what laws are justified to them, because in conceptualising the reasons that MOPs recognise we are already applying a particular standard of moderate idealisation.

The conjunctive approach seeks to rise above disagreement about the test of public justification by saying that laws should only be enacted when no citizen considers them not to be publicly justified. But if the conjunctive approach concerns the beliefs of MOPs then it must privilege a particular test of public justification, which it uses to identify MOPs' beliefs, so it cannot rise above disagreement concerning that test. Indeed, we must already assume and apply a test of public justification in order to pursue the conjunctive approach, and will then by construction find that MOPs endorse the reasons that that test of public justification 
attributes to them. In other words, one must already have a particular specification of PJP in mind in order to answer the question of what laws all citizens can reasonably accept.

It must therefore be actual Colin who objects to $\mathrm{L}_{2}$, on the basis of his test of public justification. Colin rejects Becky's test and applies a different one, according to which some MOPs lack sufficient reason to endorse $\mathrm{L}_{2}$. Wall's argument must concern this kind of disagreement, between actual citizens. The imposition of $\mathrm{L}_{2}$ does not seem to display the kind of respect for Colin's own beliefs and values - specifically actual Colin's beliefs about public justification - that convergence liberalism claims to manifest.

This understanding of Wall's argument is, I think, different from his own. He understands the argument as concerning the beliefs of MOPs. But this cannot be right, for the reason I have given - once we are talking about what MOPs believe we must have already assumed and applied some standard of moderate idealisation. Given that it is that standard itself that is under dispute, the objection must come from other actual citizens (or theorists), who apply a different standard of moderate idealisation and thus reach a different conclusion about what MOPs believe.

Once we have recognised this, however, the non-conjunctive approach to disagreement about public justification appears less troubling. Convergence liberals never claimed to respect actual citizens' beliefs about their or others' reasons. They claim to respect citizens' evaluative standards and their justificatory reasons, not their beliefs about their reasons or about legitimacy itself. This means that convergence liberals can pursue the non-conjunctive approach, and argue that, contra Wall, it is not morally authoritarian, because there is a 
normatively significant difference between Becky's disagreement with Andy and her disagreement with Colin.

\section{In defence of the non-conjunctive approach}

Andy is seeking to enforce his own view of morality's demands, in the face of reasonable disagreement among moral free and equals. For the convergence liberal, this is morally authoritarian. ${ }^{26}$ Becky is not doing this. She believes that $\mathrm{L}_{2}$ is justified to every citizen by their own reasons - that every citizen has sufficient reason to prefer $\mathrm{L}_{2}$ to having no law on the basis of their own evaluative standards, at the correct level of idealisation. Becky's understanding of the test of public justification is part of the explanation for why she believes $\mathrm{L}_{2}$ to be legitimate, and that test is controversial - Colin rejects it. But Becky is not enforcing that test upon Colin, or anyone else. She is defending a law that she believes is justified to all, on the basis of that test. She is thus attempting to treat all citizens as free and equal, according to her understanding of public justification. Becky believes that $\mathrm{L}_{2}$ is conclusively justified to every citizen, and thus its enactment would not be morally authoritarian. Andy, by contrast, is simply seeking to impose his own moral view.

Wall would find this highly dubious. After all, Colin has expressed his dissent to Becky. He has explained to her why he rejects her understanding of the test of public justification, such that he considers $\mathrm{L}_{2}$ illegitimate. If Becky continues to consider $\mathrm{L}_{2}$ legitimate then she is holding her understanding of the test of public justification, and therefore of what laws are in

\footnotetext{
${ }^{26}$ As an anonymous reviewer pointed out, Vallier arguably does not explicitly endorse the anti-authoritarian grounding for convergence liberalism. Vallier does repeatedly mention anti-authoritarianism as one of the basic ideas underlying public reason views, however, and approvingly cites Gaus's discussion of this idea. See Vallier
} (2014a, 32-33; 2014b, 2; 2016b, 351). 
the socially eligible set, to be authoritative for everyone, despite Colin's protests. Yet convergence liberalism's core claim is that all citizens are equally authoritative interpreters of the demands of morality.

Further, Andy might well believe that justifying laws using sound reasons itself respects others as free and equal. ${ }^{27} \mathrm{He}$ too is attempting to respect others as free and equal, according to his understanding of what this requires with regard to the justification of laws.

The vital point, however, is that Becky is not treating her evaluative standards as authoritative for everyone. She recognises that coercion must be justified to the coerced by their own reasons, and she thus respects others' reasons for laws, and the principles, values, and norms that those reasons are based on. Convergence liberalism never claimed to respect people's beliefs 'all the way down', as far as accommodating their beliefs about the reasongiving aspect of legitimacy itself. This is impossible, since convergence liberalism claims to be the correct theory of legitimacy - the correct account of what is required with regard to the reasons that justify laws, if laws are to be permissibly imposed. Becky believes that her view of the test of public justification is the right one, and thus that $\mathrm{L}_{2}$ is conclusively justified to every citizen according to their own belief-value sets - by reasons that are accessible to them. She believes that the enactment of $\mathrm{L}_{2}$ coercively imposes only what all citizens have sufficient internal reasons to accept, and thus respects everyone as free and equal. This is in contrast to Andy's endorsement of $\mathrm{L}_{1}$.

It is true that Colin considers Becky mistaken about the test of public justification, but convergence liberalism cannot hold that everyone's views of legitimacy must themselves be

\footnotetext{
${ }^{27}$ For an example of this view, see Arneson $(2010 ; 2014)$.
} 
respected. If Becky is sure of her own view of legitimacy, despite Colin's protests, then she rightly believes that $\mathrm{L}_{2}$ can be legitimately enacted. ${ }^{28}$ This is not to say that individuals should not listen to others' arguments and update their views about others' reasons on that basis. Indeed, convergence liberals should accept a norm of consulting those who believe that laws are not justified to them, and being ready to revise one's judgments in light of those objections, which provide strong evidence that one has misapplied idealisation. ${ }^{29}$ Often, therefore, Becky will find that others can show her that they do not have sufficient reasons for laws. ${ }^{30}$ In the case at hand, however, Becky continues to believe that she is applying moderate idealisation correctly, despite Colin's disagreement. Becky's best understanding says that $\mathrm{L}_{2}$ is publicly justified, and she does not disrespect other citizens by continuing to hold, and act on, that belief. In other words, convergence liberals should adopt the nonconjunctive approach to disagreement concerning public justification, and reject the claim that this is morally authoritarian.

Unfortunately, this argument opens the door to a further challenge. ${ }^{31} \mathrm{We}$ can see this by introducing Denise. Denise believes that at the correct level of idealisation all citizens would be Christians. There are sound philosophical arguments for God's existence and historical arguments for Jesus' resurrection and the trustworthiness of the gospels. Idealisation should include imputing information about the relevant considerations to citizens, and all would come to accept some form of Christianity after a respectable amount of good reasoning about these considerations. Denise therefore believes that law $\mathrm{L}_{3}$, which enforces a central aspect of

\footnotetext{
${ }^{28}$ My discussion here connects to Gaus's (2011, 225-232) 'affirmation of the centrality of the first-person point of view.' See also Gaus (2015b), especially pp. 153-154.

${ }^{29}$ Thanks to Kevin Vallier and an anonymous reviewer for stressing this point to me.

${ }^{30}$ Or, indeed, that they do.

${ }^{31}$ Neither Wall nor Vallier consider this further objection.
} 
Christian morality, fulfils PJP. All have sufficient reason to accept $\mathrm{L}_{3}$ according to their own moderately idealised belief-value sets, since all accept the core claims of Christianity once idealised in this way.

Becky considers Denise to be mistaken. Denise is wrong to claim that after merely moderate idealisation all citizens would be Christians. Many citizens hold views that directly conflict with Christianity; it is implausible to claim that a respectable amount of good reasoning would lead all to accept it. Denise evidently holds an incorrect test of public justification. According to any plausible test, $\mathrm{L}_{3}$ is not publicly justified, since many non-Christians lack sufficient reason to accept it. If enacted, $\mathrm{L}_{3}$ would coerce many citizens to whom it is not justified, so would fail to respect those citizens as free and equal.

The problem, however, is that Becky's objection to Denise's view is very similar to Colin's objection to Becky's view. Each claims that the other has a mistaken, over-idealising, test of public justification, and therefore permits the imposition of laws that are not publicly justified. If Becky can dismiss Colin's objection in the way that I suggested then it appears that Denise can respond to Becky in precisely the same way. Denise understands that Becky rejects her test of public justification, but nonetheless believes it to be correct, and thus that laws justified by Christianity can be permissibly enacted.

It appears that convergence liberals must accept Denise's claim here, so accept that she can believe Christian laws to be publicly justified. This would be a troubling result, however, since many citizens might believe that their own understanding of morality would be accepted by all after moderate idealisation. Convergence liberalism was supposed to prevent the enforcement of particular understandings of morality upon all citizens. This was the basis 
of its central objection to the right reasons view. Yet it now appears to fail at this. Even laws justified by particular ideas about the good might still be imposed upon everyone, when accompanied by the claim that everyone accepts that claim about the good when appropriately idealised. ${ }^{32}$

The convergence liberal response to this must be to insist that there is a truth about legitimacy. There is a fact about what is the correct test of public justification, the correct specification of PJP, and thus about what laws are within the socially eligible set. Further, citizens who claim that everyone would accept their conception of the good under moderate idealisation are mistaken. Such citizens affirm an incorrect test of public justification.

Becky believes that her view is correct. She believes that Colin's view does not idealise citizens' belief-value sets enough, while Denise over-idealises. They therefore make false claims about what moderately idealised citizens would accept. This is true even if Christianity is in fact objectively correct, and even if all citizens would recognise this under full idealisation - i.e. with full information and rationality. Given her belief that she endorses the correct test of public justification, Becky is right to object to Denise's view and continue to hold her own, even though Colin's objection to Becky's view is similar to her objection to Denise's. The difference, from Becky's perspective, is that Becky's view of legitimacy is correct, while Colin's and Denise's are not. If Becky is right about this, such that her view is indeed correct, then that view should be followed by the polity, and the others' should not be.

Parallels can obviously be drawn between this proposed convergence liberal response and the right reasons view. The right reasons view says that whatever our disagreements about

\footnotetext{
${ }^{32}$ For a similar objection, see Eberle (2005).
} 
morality, laws justified by the true morality can be enforced - and, indeed, that this respects citizens as free and equal, since all have reason to follow the true morality. Similarly, convergence liberalism says that whatever our disagreements about public justification, the correct test of public justification should be followed, since this is what is required by respect for citizens. The defence of convergence liberalism I just presented appears the same as the defence the right reasons view makes against convergence liberal claims.

The convergence liberal must hold that the difference here is that the right reasons view is an incorrect view of legitimacy, which coerces individuals in ways that are not justified to them, and thus fails to treat them as free and equal. Convergence liberalism is the correct theory of legitimacy, since it respects citizens as free and equal by only enforcing laws that are conclusively justified to every citizen.

Clearly we will disagree about precisely which laws are conclusively justified to all, and thus about which laws are legitimate. This is inevitable; convergence liberalism does not claim to avoid all controversy (Gaus 2013b, 79-80). Sometimes, a law might be enacted that its proponents believe is publicly justified but that some believe is not justified to them, such that they are being impermissibly coerced. In such cases, the objectors should be carefully listened to, and their complaints taken seriously. Often they will be able to demonstrate that the law is not in fact conclusively justified to them. At times, however, advocates of the law might continue to believe that it is justified to the objectors - and they might be right about this. 
The convergence liberal theorist must present what she believes to be the correct account of legitimacy, and the correct specification of PJP. ${ }^{33}$ This will be controversial, but to the extent that the theorist has the correct view, that view correctly assesses when laws respect citizens as free and equal, even if some reject it. What matters, for the convergence liberal, is that laws are in fact conclusively justified to all citizens. Disagreement about whether laws are so justified, flowing from disagreement about the precise test of public justification, does not undermine the theory. In other words, what matters is that laws are in fact in the socially eligible set, not that everyone agrees that laws are in that set. ${ }^{34}$

An analogy can be drawn here with actual consent theory. Many political philosophers believe that actual unanimous informed consent to a law is sufficient for its legitimacy. This is the case even though no one has consented to consent theory. Even if some citizens reject the sufficiency of actual consent, such theorists would not think that this undermines the legitimacy of a law that has received such consent. Their confidence in unanimous consent as providing legitimacy means they reject complaints about the legitimacy of such a law.

\footnotetext{
${ }^{33}$ Clearly I have not done this - or even attempted to do so - in this paper.

${ }^{34}$ Lister $(2013,100-101)$ argues that this will undermine the authority of the state. Disagreement about what laws are in the socially eligible set means that convergence liberalism has philosophically anarchist implications, since citizens will be free to disobey laws that they do not consider to be publicly justified. I do not think that this is the case, however, especially if we see convergence liberalism as primarily being a view about the moral permissibility of state coercion. This leaves open the possibility that citizens might be obligated to obey laws that they do not believe to be publicly justified. Further, all views of legitimacy face analogous problems, since the legitimacy of any particular law will depend on the details of how the theory of legitimacy is specified, and there will be disagreement about this specification, and thus about whether laws are legitimate. Unfortunately I lack space to develop this response to Lister's claim here.
} 
Convergence liberalism's response to disagreement about public justification is similar. Some will reject the correct theory of legitimacy. But this does not stop it being the true theory, or mean that publicly justified laws do not respect all citizens as free and equal. If Becky's understanding of legitimacy is correct then she rightly objects to Denise's view and rightly rejects Colin's objection, despite the apparent similarity between these objections. Just as actual consent theory respects people's actual consent but does not need to respect their views about actual consent theory itself, convergence liberalism respects people's evaluative standards and their moral freedom and equality, even if sometimes laws are enacted which some consider to not be in the socially eligible set, due their mistaken understandings of legitimacy.

\section{Concluding comments and implications}

Even if my argument succeeds, it might appear to have costs, from a convergence liberal perspective. In closing, I will discuss two prima facie costs, and argue that neither survives critical scrutiny.

Firstly, I have acknowledged a structural similarity between convergence liberalism and the right reasons view, which might seem to reduce the distance between them. Both of these views, and indeed the consensus public reason liberal view, can be understood as having two main features. First, they specify a justificatory constituency, and in particular the reasons endorsed by members of this constituency. Second, they claim that laws are legitimate when justified to that constituency, because such justification shows respect for the freedom and equality of all citizens. Convergence liberals object to the right reasons view's justificatory constituency on the grounds that it fails to truly respect actual citizens and their reasonable 
disagreements, since the constituency is defined as those who endorse sound reasons. ${ }^{35}$ Convergence liberals also object to the justificatory constituency specified by consensus public reason liberals, both because it is too narrow and because it does not ensure conclusive justification, due to its exclusion of all unshared reasons. Nonetheless, convergence liberalism itself does not see all of citizens' actual beliefs and values as constraining state coercion. It includes a normative standard of reasonableness and an account of epistemic idealisation. Further, it holds that publicly justified laws can be imposed even if some citizens do not believe them to be publicly justified.

This does not mean that these theories are normatively indistinguishable, or that convergence liberalism loses its attractiveness, however. Convergence liberals can continue to object to both the right reasons view and consensus public reason liberalism, on the grounds that the narrowness of their justificatory constituencies reflects a mistaken view about respect for citizens' freedom and equality. Ultimately, the dispute between these three views is about what such respect requires with regard to the nature of the justificatory constituency, and what it means to achieve 'justification to' this constituency. Like the other views, convergence liberals have to argue that their answers to these questions are correct and others' answers are incorrect - no matter what actual citizens think about this. Convergence liberals are sometimes accused of portraying themselves as somehow above the fray, or as not engaged in conventional moral and political philosophy (Enoch 2013:174-176). While it is true that convergence liberals have a more capacious view of the justificatory constituency, and allow a broader range of citizens' reasons and values to play a role in public justification, my argument suggests that they are not above the fray. But this is not a problem or cost.

\footnotetext{
35 As Lister $(2013,40)$ notes 'correctness justification is simply public justification with the circle of qualification reduced to one.'
} 
Secondly, my argument might appear incompatible with Gaus's broader project of achieving a publicly justified social morality, or a 'public moral constitution' (Gaus 2013a; 2015a). As I noted in Section 1, my focus has been on convergence liberalism applied to coercive laws. It is possible that convergence liberals who also apply PJP to social morality and moral demands more generally could not endorse my argument.

I claim that confronting disagreement concerning public justification forces convergence liberals to assert that they affirm the true moral principle about legitimate coercion, irrespective of what anyone thinks about it. This seems to be in tension with Gaus's desire for all to be able to recognise the moral demands that are placed upon them - including by law as justified from their own perspective. Of course, even on my account, the convergence liberal holds that publicly justified laws are endorseable from the perspective of every citizen, since they are conclusively justified to every citizen on the basis of their own evaluative standards. But citizens who reject PJP, or endorse a different specification of it, might consider some of those laws not to be justified to them. In my view, convergence liberals must accept this, but hold that such laws are nonetheless publicly justified and permissibly enforceable. Gaus might consider this problematic, since it might seem to mean that many citizens will not actually recognise the authority of laws, and it relies on an assertion of the truth of a particular claim about legitimacy that some reasonably reject. On my account, convergence liberalism is about the truth of legitimacy and the constraints this places on government action. This seems to contrast with Gaus's focus on social morality and moral coordination. To use Gaus's (2013a) terminology, my argument makes convergence liberalism into moral philosophy rather than moral theory. ${ }^{36}$

\footnotetext{
${ }^{36}$ Gaus is here drawing on a distinction made in Rawls (1974-1975).
} 
It is not clear how great the distance is between my view and Gaus's, however. Gaus (2011, 225-228) rejects RR and holds that a standard of 'justification to others', including a view about others' justificatory reasons, can be followed even if those others do not endorse it. Perhaps this means that my argument is compatible with Gaus's view.

Indeed, I think Gaus would ultimately have to make an argument similar to mine in response to disagreement about the test of public justification, even if he would be reluctant to do so. Gaus $(2011,183-232)$ argues that a commitment to public justification is an endogenous commitment of our social morality, since it is a presupposition of our reactive attitudes. Social morality is 'the set of social-moral rules that require or prohibit action, and so ground moral imperatives that we direct to each other to engage in, or refrain from, certain lines of conduct' (Gaus 2011, 2). Gaus argues that our reactive attitudes of resentment and indignation toward others when they violate a social-moral rule can only be rationally wellgrounded if those others have sufficient reason to endorse that rule. This seemingly gives him more resources to respond to disagreement about public justification, since he can argue that anyone who engages in standard social-moral practices of imposing moral demands on others, and blaming and feeling resentment toward those who violate those demands, is already implicitly committed to a public justification principle. Even if Gaus's argument concerning the reactive attitudes succeeds, however, ${ }^{37}$ there will be disagreement among actual citizens about the precise test of public justification - about precisely what it means to say that others have sufficient reason to endorse a moral rule and about what reasons individuals have. Gaus will have to assert that one such test is correct. Now, he might hold that our social-moral practices themselves determine what is the correct test (for us). Our

\footnotetext{
${ }^{37}$ For a critique of that argument, see Taylor (forthcoming).
} 
understanding of the reasons that we have itself has a social dimension, so we should be ready to listen to others' reasoning and to change our views about the reasons that they, and we, have (Gaus 2011, 251-253). Even then, however, disagreement about the correct understanding of our social practices and their endogenous commitments will remain. There will thus be remaining disagreement about the reasons that we have. Again, I think Gaus would ultimately have to endorse a particular test of public justification as correct, and so adopt a non-conjunctive approach. ${ }^{38}$

Defending the non-conjunctive approach to disagreement concerning public justification from the charge of moral authoritarianism, as I have done in this paper, is a matter of showing that convergence liberalism is coherent, rather than that it is sound or plausible. My argument in this paper does not in itself give us positive reason to endorse convergence liberalism. If the argument is successful, however, then it means that convergence liberalism cannot be dismissed as internally inconsistent. Instead, the fate of the view depends on the plausibility of its substantive position regarding how we can treat one another as free and equal moral agents when imposing coercive laws.

\footnotetext{
${ }^{38}$ The fact that Gaus applies this test at the level of moral demands gives rise to a distinct self-defeat objection pressed by Enoch $(2013,170-173)$. Enoch points out that Gaus makes moral demands of others on the basis of his Basic Principle of Public Justification (BPPJ; see Gaus 2011, 263). Yet some lack sufficient reason to endorse BPPJ, so BPPJ itself rules out those moral demands. BPPJ cannot be the basis for moral demands without self-defeat. This argument does not apply to the view I have discussed in this paper, since my focus has exclusively been on coercive laws. One could accept convergence liberalism at the level of coercive laws while rejecting its application to moral demands more generally, and thus avoid Enoch's objection. I am agnostic here as to the success of Enoch's objection against Gaus's view. As Vallier (2016b, 360) notes, Gaus seemingly could avoid the objection simply by refraining from making moral demands based on BPPJ. Indeed, Gaus could hold BPPJ to be true and criticise others' characters, attitudes or moral judgments that contradict BPPJ without making moral demands based on BPPJ.
} 


\section{Acknowledgments}

I owe thanks for comments on earlier versions of this paper to Thomas Sinclair, Anthony Taylor, Kevin Vallier, the participants in the 2015 MANCEPT Workshop on Theories of Public Reason, and several anonymous reviewers. I owe particular thanks to Andrew Lister, for extensive and extremely helpful written comments.

\section{Funding}

This research received no specific grant from any funding agency in the public, commercial, or not-for-profit sectors. I started this research while I was a DPhil student at the University of Oxford. My DPhil research was funded by an Arts and Humanities Research Council (AHRC) studentship.

\section{Notes on contributor}

Paul Billingham is a Junior Research Fellow in Political Philosophy at Christ Church, University of Oxford. His work focuses on debates within political liberalism and concerning the place of religion within public life, and has been published in various journals in moral, political and legal philosophy, including Politics, Philosophy \& Economics, Journal of Moral Philosophy, Social Theory and Practice, and Oxford Journal of Law and Religion.

\section{References}

Arneson, Richard. 2010. “Against Freedom of Conscience.” San Diego Law Review 47(4): 1015-1040.

Arneson, Richard. 2014. "Rejecting The Order of Public Reason." Philosophical Studies 170(3): 537-544. doi: 10.1007/s11098-013-0268-6. 
Billingham, Paul. 2016. "Convergence Justifications Within Political Liberalism: A Defence.” Res Publica 22(2): 135-153. doi: 10.1007/s11158-015-9278-x.

Billingham, Paul. Forthcoming. "Review Essay: Consensus, Convergence, Restraint, and Religion.” Journal of Moral Philosophy.

Boettcher, James W. 2015. “Against the Asymmetric Convergence Model of Public Justification." Ethical Theory and Moral Practice 18(1): 191-208. doi: 10.1007/s10677014-9519-7.

D’Agostino, Fred. 2013. “The Orders of Public Reason.” Analytic Philosophy 54(1): 129155. doi: 10.1111/phib.12009.

D’Agostino, Fred, and Gerald Gaus. 1998. "Public Reason: Why, What and Can (and Should) it Be?" In Public Reason, edited by Fred D'Agostino and Gerald Gaus, xi-xxiii. Aldershot: Ashgate Dartmouth.

Eberle, Christopher J. 2005. “What Does Respect Require?” In Religion in the Liberal Polity, edited by Terence Cuneo, 173-194. Notre Dame, Ind.: University of Notre Dame Press.

Enoch, David. 2013. “The Disorder of Public Reason.” Ethics 124(1): 141-176. doi: $10.1086 / 671386$.

Estlund, David. 2008. Democratic Authority: A Philosophical Framework. Princeton, N.J.: Princeton University Press.

Gaus, Gerald. 1996. Justificatory Liberalism. New York: Oxford University Press.

Gaus, Gerald. 2010a. "On Two Critics of Justificatory Liberalism: A Response to Wall and Lister." Politics, Philosophy \& Economics 9(2): 177-212. doi: $10.1177 / 1470594 X 09345678$. 
Gaus, Gerald. 2010b. “The Place of Religious Belief in Public Reason Liberalism. In Multiculturalism and Moral Conflict, edited by Maria Dimovia-Cookson and Peter M.R. Stirk, 19-37. New York, NY: Routledge.

Gaus, Gerald. 2011. The Order of Public Reason: A Theory of Freedom and Morality in a Diverse and Bounded World. Cambridge: Cambridge University Press.

Gaus, Gerald. 2012. "Sectarianism Without Perfection? Quong's Political Liberalism.” Philosophy and Public Issues (New Series) 2(1): 7-15.

Gaus, Gerald. 2013a. "On the Appropriate Mode of Justifying a Public Moral Constitution." The Harvard Review of Philosophy 19: 4-22. doi: 10.5840/harvardreview2013191.

Gaus, Gerald. 2013b. “On Theorizing About Public Reason.” European Journal of Analytic Philosophy 9(1): 64-85.

Gaus, Gerald. 2015a. “On Dissing Public Reason: A Reply to Enoch.” Ethics 125(4): 10781095. doi: $10.1086 / 680904$.

Gaus, Gerald. 2015b. "Private and Public Conscience." In Reason, Value, and Respect: Kantian Themes from the Philosophy of Thomas E. Hill Jr, edited by Mark Timmons and Robert N. Johnson, 135-157. New York: Oxford University Press.

Gaus, Gerald, and Kevin Vallier. 2009. "The Roles of Religious Conviction in a Publicly Justified Polity: The Implications of Convergence, Asymmetry and Political Institutions." Philosophy \& Social Criticism 35(1-2): 51-76. doi: 10.1177/0191453708098754.

Lister, Andrew. 2013. Public Reason and Political Community. London: Bloomsbury Academic.

Quong, Jonathan. 2011. Liberalism Without Perfection. Oxford: Oxford University Press. Rawls, John. 1974-1975. “The Independence of Moral Theory.” Proceedings and Addresses of the American Philosophical Association 48: 5-22. doi: 10.2307/3129858. 
Rawls, John. 2005. Political Liberalism, expanded edition. New York: Columbia University Press.

Solum, Lawrence B. 1993. "Constructing an Ideal of Public Reason.” San Diego Law Review 30(4): 729-762.

Taylor, Anthony. Forthcoming. "Public Justification and the Reactive Attitudes." Politics, Philosophy \& Economics.

Tyndal, Jason. 2015. "Moderate Idealization and Information Acquisition Responsibilities." Res Publica. Advance online publication. doi: 10.1007/s11158-015-9295-9.

Vallier, Kevin. 2012. "Liberalism, Religion and Integrity.” Australasian Journal of Philosophy 90(1): 149-165. doi: 10.1080/00048402.2011.560612.

Vallier, Kevin. 2014a. Liberal Politics and Public Faith: Beyond Separation. Oxford: Routledge.

Vallier, Kevin. 2014b. “On Jonathan Quong's Sectarian Political Liberalism.” Criminal Law and Philosophy. Advance online publication. doi: 10.1007/s11572-014-9350-1.

Vallier, Kevin. 2016a. "In Defense of the Asymmetric Convergence Model of Public Justification: A Reply to Boettcher.” Ethical Theory \& Moral Practice 19(1): 255-266. doi: 10.1007/s10677-015-9605-5.

Vallier, Kevin. 2016b. "Public Reason is Not Self-Defeating." American Philosophical Quarterly 53(4): 349-363.

Wall, Steven. 2002. “Is Public Justification Self-Defeating?” American Philosophical Quarterly 39(4): 385-394.

Wall, Steven. 2013a. "Public Reason and Moral Authoritarianism." The Philosophical Quarterly 63(250): 160-169. doi: 10.1111/j.1467-9213.2003. 
Wall, Steven. 2013b. "Political Morality and Constitutional Settlements." Critical Review of International Social and Political Philosophy 16(4): 481-499. doi:

10.1080/13698230.2013.810389. 